Res Pública Revista de Historia de las Ideas Políticas

ISSN: $1131-558 \mathrm{X}$

http://dx.doi.org/10.5209/rpub.648392

\title{
La filosofía del derecho de Schopenhauer fuera de su sistema filosófico de Carl Schmitt (1913). Un texto académico de naturaleza polémica
}

\author{
Héctor del Estal Sánchez*
}

Sumario. 1. Introducción. 2.Algunas indicaciones sobre la traducción del texto de Schmitt.

Cómo citar: del Estal Sánchez, H. (2020). La filosofía del derecho de Schopenhauer fuera de su sistema filosófico de Carl Schmitt (1913). Un texto académico de naturaleza polémica. Res Pública. Revista de Historia de las Ideas Politicas, $23(1), 109-113 .{ }^{123}$

\section{Introducción}

La filosofía del derecho de Arthur Schopenhauer no se encuentra, en modo alguno, entre los núcleos temáticos más exitosos de su pensamiento. Mientras que su pesimismo, su estética, su metafísica de la voluntad o sus aforismos sobre la sabiduría de la vida se encuentran entre los lugares más frecuentados por estudiosos, artistas, y literatos, su Rechtslehre constituye un paraje casi olvidado que solo ha contado con las visitas de algunos curiosos y en el que únicamente se han adentrado unos pocos e intrépidos exploradores. De entre estos últimos destaca la figura inesperada de un audaz aventurero: el joven Carl Schmitt, quien emprendió una expedición hacia los territorios de la doctrina del derecho schopenhaueriana en un pequeño artículo de 1913 titulado Schopenhauers Rechtsphilosophie außerhalb seines philosophischen Systems.

Este documento, que aquí presentamos en lengua castellana, pertenece al período inmediatamente posterior a la finalización de los estudios de derecho de Carl Schmitt en la Universidad de Estrasburgo, cuando en 1910 el joven jurista inicia sus primeros pasos para hacer carrera en el mundo de la jurisprudencia trabajando como asistente en el Oberlandsgericht de Düsseldorf, en las oficinas del Justizrat Hugo Lampert; un puesto que ocupa hasta que es movilizado y trasladado a Múnich en 1915, en las primeras etapas de la Primera Guerra Mundial. Para Schmitt, éstos son años de un vívido interés por el arte, la filosofía, la literatura y la música en el terreno intelectual y espiritual, pero también lo son de pasión y angustia en lo personal: las anotaciones de sus diarios de 1912-1915² son una buena muestra tanto de la profunda impresión que en él produjo el contacto con las vanguardias y la lectura de la poesía de Theodor Däubler como de la convulsa vida interior provocada por su relación amorosa con Pawla Dorotić, su-siempre heterodoxa- confesión católica y la incertidumbre por su futuro económico y profesional ${ }^{3}$. Como resultado de este escenario vital poliédrico, entre 1910 y 1915 su producción científica, representada por Ley y juicio. Examen sobre el problema de la praxis judicial (1912) y El valor del Estado y el significado del individuo (1914), coexiste con los escarceos literarios de obras como la satírica Schattenrisse (1913), publicada bajo el pseudónimo de Johannes Negelinus, en la que Schmitt dirige una mordaz e irónica crítica contra la literatura, la ciencia y la política alemanas del cambio de siglo y prefigura ya algunas de las intuiciones que posteriormente cristalizarán en Romanticismo político (1919).

En este contexto se sitúa como un trabajo de carácter jurídico-académico ${ }^{4}$ y polémico el artículo La filosofía del derecho de Schopenhauer fuera de su sistema filosófico de 1913. En él, Carl Schmitt coloca bajo el afilado bisturí de su análisis las nociones de derecho e injusticia ofrecidas por Schopenhauer para dar réplica a Erich Jung, quien un año antes había publicado Das Problem des natürlichen Rechts; una obra en la que tomaba el concepto schopenhaueriano de injusticia como punto de partida teórico para fundamentar una nueva doctrina del derecho natural que fuese capaz de hacer frente a las limitaciones con las que se topaba el iuspositivismo en la praxis de la vida jurídica.

Universidad de Salamanca

hedesa@usal.es

C. Schmitt, Tagebücher. Oktober 1912 bis Februar 1915, hrsg. Ernst Hüsmert, Berlin, Akademie Verlag, 2005.

Un análisis del contenido de estos diarios puede encontrarse en: J. W. Bendersky, "Schmitt's Diaries", en J. Meierhenrich y O. Simons (eds.), The Oxford Handbook of Carl Schmitt, New York, Oxford University Press, 2016, pp. 120-125.

3 De carácter académico, encontramos también en este período artículos como: "Über Tatbestandsmässigkeit und Rechtswidrigkeit des kunstgerechten operativen Eingriffs", Zeitschrift für die gesamte Strafrechtswissenschaft, 31 (1910), pp. 467-478; y "Juristische Fiktionen (über Vaihinger und die Philosophie des Als-Ob)", Deutsche Juristen-Zeitung XVIII, 12, 1913, pp. 804-806. 
La crítica schmittiana a la filosofía del derecho de Schopenhauer en el artículo polémico está destinada a mostrar que ésta no puede ser utilizada como fundamento de un sistema filosófico-jurídico (tal como pretende Jung) debido a que su concepto de derecho, antes que esclarecer cuál es la esencia del derecho, la "niega". Lo que Carl Schmitt pone en juego en el texto es una aplicación específica de las ideas rectoras que están a la base de su tesis de habilitación: si en El valor del Estado... Schmitt demuestra de un modo sistemático la imposibilidad erigir una filosofía del derecho que tome al individuo por su piedra de toque, en La filosofía del derecho de Schopenhauer... muestra el fracaso de ese proyecto en el caso concreto de Schopenhauer y Jung ${ }^{4}$.

El argumento central que esgrime Carl Schmitt es que, en el fondo, el concepto schopenhaueriano de injusticia, del que se deriva después el de derecho, no se desprende de la idea cósmica de la voluntad de vivir schopenhaueriana, sino de un ensalzamiento desmesurado del valor del individuo: cuando Schopenhauer define la injusticia como negación de la voluntad a causa de la acción de otro, de lo que se trata siempre -arguye Schmitt- es de una voluntad individual y, en consecuencia, la "legítima defensa" como negación de la injusticia y fenómeno originario del derecho, colocaría el origen del derecho mismo en la individualidad: todo derecho sería, desde esta perspectiva, el derecho inidividual "a la existencia y a la no negación".

Esta exaltación del individuo y de su significado para el derecho en el sistema filosófico-jurídico schopenhaueriano-junguiano, señala Carl Schmitt, no es otra cosa que una "subrepción de la carga probatoria" en la fundamentación del derecho, pues todo derecho individual es una "construcción jurídica" y, como tal ha de ser posterior a un verdadero concepto de derecho: ambos presuponen, precisamente, aquello que se debería demostrar al situar la individualidad y su derecho a la "no negación" como punto de apoyo de sus doctrinas del derecho. Ahora bien, lo que verdaderamente subyace a esta crítica desborda lo que Carl Schmitt puede expresar dentro los límites formales del artículo como trabajo científico-académico para una revista jurídica: en el escrito polémico, el joven jurista aplica específicamente a Schopenhauer el anti-individualismo jurídico presente en todas sus obras tempranas basado en la convicción de que la norma existe con anterioridad a todo individuo y que éste solo cobra sentido cuando cumple su función dentro del Estado, cuya misión es la de realizar el derecho en la Tierra ${ }^{5}$. Concebir, tal y como hacen Jung y Schopenhauer, el Estado y el derecho como un instrumento al servicio de la seguridad y de los intereses egoístas de los individuos desprovee de dignidad y de verdadera legitimación al primero en la misma medida que niega la esencia del segundo como norma elevada y objetiva.

R. Mehring, Carl Schmitt. Aufstieg und Fall. Eine Biographie, München, C. H. Beck, 2009, pp. 59 ss.

J. L. Villacañas Berlanga, Poder y conflicto. Ensayos sobre Carl Schmitt, Madrid, Biblioteca Nueva, 2008, p. 31.

\section{Algunas indicaciones sobre la traducción del texto de Schmitt}

Antes de dar paso a nuestra traducción de La filosofía del derecho de Schopenhauer fuera de su sistema filosófico (1913) de Carl Schmitt, debemos ofrecer unas breves aclaraciones sobre la misma. El lector advertirá enseguida que en ella hacemos un uso impropio en castellano de las mayúsculas cuando empleamos la palabra "derecho". Frente a la convención establecida en español de la corrección de usar siempre minúscula en todo uso de "derecho", nosotros hemos optado aquí, con el fin de evitar cualquier anfibología posible, por escribir "Derecho" cuando Carl Schmitt se refiere al derecho en general y "derecho" cuando en el texto esta palabra tiene que ver con derechos concretos o se hace uso de ella en expresiones como "derecho a", "con más derecho" u otras similares.

Para facilitar una mayor comprensión del texto hemos considerado oportuno indicar entre corchetes y en itálicas algunas expresiones alemanas para algunos términos relevantes.

\section{La filosofía del derecho de Schopenhauer fuera de su sistema filosófico ${ }^{6}$}

Dr. JuR. Carl Schmitt, Düsseldorf

Uno de los primeros y más apasionados impugnadores [Bekämpfer] de la creencia en la omnisciencia y omnipotencia de la ley positiva, ERICH JUNG, ha dado hace poco una detallada exposición de su perspectiva metodológica sobre el derecho natural ${ }^{7}$. El punto de partida de sus argumentos, la verdadera fundamentación filosófico-jurídica del sistema, la ha tomado JUNG, tal y como confiesa abiertamente, de SCHOPENHAUER; al cual ha señalado en repetidas ocasiones como su punto filosófico de orientación. La filosofía del derecho de Schopenhauer, conocida por su oposición a toda interpretación evolucionista del Derecho, máxime a una biologicista, debe ser examinada desde sus presupuestos con motivo de este renovado intento de utilizarla no para hacer valer una perspectiva histórico-evolutiva [entwicklungsgeschichtliche] del derecho, sino para determinar su utilidad como fundamento de un sistema filosófico-jurídico.

La pregunta fundamental de toda filosofía del derecho es la pregunta por el Derecho: no por una aclaración terminológica que contenga un breve resumen de lo que la terminología común incluye bajo esta palabra; tampoco la pregunta que se responde con una explicación de manual [Kompendien-Erklärung], es decir, [la explicación de] que el Derecho objetivo sería una encarnación de las reglas de convivencia de los seres humanos; sino la pregunta acerca de la esencia del Derecho. Con ello se ha sacado el problema fuera de la esfera de un tratamiento que trabaja con los medios de la estadística o de las indagaciones de las ciencias naturales y sociales. De

(N. del T.): C. Schmitt, "Schopenhauers Rechtsphilosophie außerhalb seines philosophischen Systems", en Monatsschrift für Kriminalpsychologie und Strafrechtsreform X, 1 (abril de 1913), pp. 2731.

(N. del A.): Das Problem des natürlichen Rechts, Leipzig, 1912. 
la esencia del Derecho debe obtenerse su fundamentación y su sentido; $\mathrm{y}$, del mismo modo, [solo] después de [alcanzar] un acuerdo [Einigung] sobre la esencia del Derecho, se tiene la facultad científica de especificar la valoración de los fenómenos relacionados con la vida jurídica, la comprensión en conjunto de un periodo de la historia del derecho en una época, el juicio de valor sobre tal época particular del Derecho y el curso, el desarrollo de su sucesión ordenada. Sin embargo, cuando Schopenhauer determina negativamente la esencia del Derecho [Rechts] como negación de la injusticia [Unrechts], desde el principio debe estimularse la reflexión para la correcta apreciación del significado del problema. Pues en una definición tal descansa una expresión del convencimiento común de que en realidad todo lo positivo sería la negación de un negativo y que este negativo constituiría la propia esencia [del Derecho] (y no meramente [su] perífrasis lingüística) o apuntaría hacia una formulación determinada mediante el curso de la exposición, la cual empieza por lo injusto como lo más fácil de explicar. Una definición tal se integra en magnífica arquitectónica en el sistema de la filosofía de Schopenhauer. Sin embargo, con ello no se explica la esencia del Derecho, sino que se niega. Por ello es necesaria una demostración precisa de sus presupuestos antes de hacer de ellos la fundamentación de un sistema filosófico-jurídico; y aún más: [es] ahí donde tiene que esclarecerse una polémica metodológica actual sobre esta fundamentación.

Si el Derecho es la injusticia negada, la definición de la injusticia dará en mayor o menor medida [alguna] información acerca del Derecho. Ahora bien, según Schopenhauer la injusticia consiste en lo siguiente: que el individuo afirma la voluntad propia que se objetiva en su cuerpo hasta la negación de la voluntad ajena en otro individuo; no se da en sentido estricto ninguna injusticia contra el Estado o la colectividad [Gesamtheit], y el "derecho" del Estado para castigar no significa nada más que [el derecho] de una gran masa de individuos particulares a dar respuesta a la negación [de su voluntad] al basarse todo derecho, en el fondo, en el individuo particular. Siempre se trata, entonces, de la voluntad individual, no de la voluntad general que es esencial a toda vida y a todo fenómeno. Las expresiones ["] afirmación["] y ["]negación["] de la voluntad individual presuponen individualidades independientes [selbständige Individualitäten] que, en cuanto tales, pueden defenderse de una negación, y cuyo valor consiste, por ello, en su individualidad. Por lo tanto, para el Derecho no entra en consideración la voluntad, sino la individualidad, la cual tendría derecho a la existencia [Existenz] y a la no-negación frente al otro. Sin embargo, con ello se suprimiría la construcción [de la teoría del Derecho] a partir de la "voluntad", a la que SCHOPENHAUER otorga tanto valor. Deja sin explicar de dónde proviene el derecho del individuo a la no-negación [de su voluntad] por [la acción] de otro individuo; [no explica] por qué una negación tal de la voluntad individual tiene que ser, como tal, injusticia. Si la afirmación de la propia voluntad que se excede hasta la negación de la voluntad ajena es injusticia, entonces, dentro de los límites en los que no llegue hasta la negación [de una voluntad ajena] no es injusticia; [y] la afirmación de la propia voluntad frente a una negación [de la misma] sería, por otra parte, justicia [Recht]. Las definiciones de Derecho y de injusticia presuponen dos voluntades similares, las cuales existen la una junto a la otra y de las cuales cada una puede negar a causa de la negación que comete la otra. La razón de esto [es] que puede encontrarse la ilegitimidad de la primera negación $\mathrm{y}$, en cambio, para su ilegitimidad no puede darse mayor razón aparte de que se permite afirmar hasta un cierto límite más allá del cual comienza la injusticia.

Aquí se pone de manifiesto cómo al filósofo se le escapa lo que propiamente constituye [tanto] la injusticia [como] el Derecho, para reemplazarlo por las palabras ["]afimación["] y ["]negación["], las cuales son totalmente vacías en la medida en que no reciben contenido alguno mediante una indicación sobre cuándo la afirmación [de la voluntad] es legítima y cuándo la negación [de la voluntad] es ilegítima. La definición que ScHoPENHAUER da de la injusticia termina con otras palabras: que injusticia es lo que de un modo legítimo no se está obligado a aceptar [was man sich berechtigterweise nicht gefallen zu lassen braucht]. Esto no tiene por resultado ningún tipo de indicio acerca de dónde está el límite entre afirmación y negación. Pues por el mero hecho de mi existencia corpórea niego a cualquier otro individuo. Por el mero hecho de la impenetrabilidad de mi cuerpo material, por ejemplo, impido que otro esté donde yo estoy. Por qué esto no es ninguna negación en el sentido del Derecho, debe poderse derivar de la fundamentación que se dé al Derecho respecto a la injusticia. Si las palabras ["]afirmación["] y ["]negación["] significan algo específico en la esfera del Derecho, si la voluntad individual, que tiene un derecho a la no-negación, es una construcción jurídica, entonces se suprime la construcción de Schopenhauer y deviene, allí donde se trata de [su] utilización independiente en un sistema filosóficojurídico fuera del sistema filosófico de ScHOPENHAUER, una transcripción de las preguntas elementales que forman el punto de partida de la filosofía del derecho. Con la proclamación de la injusticia como el concepto primario y la deducción del Derecho a partir de ella como su negación no se ha hecho ningún avance en el conocimiento. La norma descansa tanto en el concepto de la injusticia como en el del Derecho, y las palabras ["]afirmación["] y ["]negación["] contienen ya en sí los elementos normativos en torno a cuya fundamentación gira todo: su planteamiento como punto de partida no significa más que la subrepción de las premisas sobre las que debe recaer la prueba. Para Schopenhauer el Derecho no es un nihil privatum, un concepto de la ausencia de un objeto. Puesto que el Derecho no existe sin más donde no hay injusticia, sino que más bien el Derecho consiste en una negación de la injusticia, [el Derecho] es, por lo tanto, el acto positivo de la negación [Negation]. Todo Derecho es, según su esencia, legítima defensa [Notwehr]. Según una consideración más precisa, el Derecho aparece como algo absolutamente positivo al que solo es dada una formulación en relación con la negación [Verneinung]. La negación categórica de la injusticia presupone un acto de legítima defensa, una toma 
de posición, y esta es, precisamente, la que se somete a la calificación de "justa". Precisamente en ella descansa lo esencial del Derecho.

Si se analizan más de cerca las explicaciones de Schopenhauer, se encontrará que él también [ha] utilizado en ellas las expresiones "Derecho", "con más derecho", etc. [en un contexto] donde éstas no tienen ninguna relación con una negación de la injusticia. Así, un "derecho" sobre las cosas debe fundamentarse mediante el trabajo, mediante la "formación" [Formation]. Sin embargo, esto debe ser posible solo si no se dañan otros "derechos", como se explica a continuación: en lo relativo a la teoría del derecho de primera ocupación [Präokkupationsrecht], el nuevo recién llegado podría oponerse "con mucho mejor derecho" a cualquier otro que se apoye en el derecho de primera ocupación: precisamente porque el otro ha disfrutado ya mucho, sería justo que ahora también le llegue una vez a él su turno ${ }^{8}$. Todos estos argumentos, que normalmente empujan a un juego ambiguo con la palabra ["]Derecho["], no exponen nada del Derecho como negación de la injusticia. En ellos se hace evidente cómo en aquel lugar la palabra "Derecho" aparece así formulada como negación negada, pero el valor cognoscitivo de la definición a partir de la negación está en entredicho y es completamente ilusoria en este caso.

La negación de la voluntad ajena es injusticia. Toda injusticia, bien sea violencia o artimaña, debe consistir en lo siguiente: en que un individuo ajeno ha sido obligado a servir a mi voluntad en vez de a la suya propia. Para Schopenhauer, de ello debería resultar la consecuencia de introducir, en la medida en que el Derecho esté en cuestión, al individuo como sujeto por sí solo y prescindir de aquella voluntad general y supraindividual. Ahora bien, si el Estado como comunidad hace responsable a los individuos, si va tan lejos que ejecute una pena de muerte [Hinrichtung] - "con pleno derecho" dice Schopenhauer-, se plantea la pregunta acerca de cómo se fundamentaría este pleno derecho. Tomado en sentido estricto, solo tiene derecho a la negación de la negación aquel cuya voluntad es negada en un caso concreto. Por el asesinato sería [negada] la del asesinado. La voluntad de vivir en los seres humanos restantes no es negada en este caso; a lo sumo podría decirse en otro sentido que [es negada], quizás, no la voluntad de vivir directamente, sino la voluntad de seguridad y de no estar expuesto al peligro [Ungefärhdetheit]; y como negación de esta negación, aparece entonces la ejecución de la pena de muerte, [pero] no como negación de la negación de la voluntad de vivir que rige en [el caso] del asesinado. Con esta construcción, sin embargo, cada particular que está amenazado debe tener el derecho de ejecutar la pena de muerte. Si el Estado debe tenerlo en oposición a los individuos particulares, entonces es necesario que para él haya una voluntad específicamente distinta de la voluntad particular, la cual quizás puede ser fácilmente "construida", pero fundamentarla, sin embargo, no es

(N. del T.) Tanto la expresión como el ejemplo se encuentran en: A. Schopenhauer, El mundo como voluntad y representación. Volumen I, trad. R. Rodríguez Aramayo, Madrid, F.C.E./Círculo de Lectores, 2003, pp. 434 ss. fácil. Si alguien aceptase que el pariente del asesinado tiene un derecho de venganza, podría, en efecto, establecer fácilmente una construcción en el sentido de que también la voluntad del familiar como tal habría sido vulnerada por aquel daño de la voluntad de una persona; y una suerte de voluntad familiar existiría, la cual se correspondería con una sustancia familiar. Esto, claramente, no sería una fundamentación. La tautología en todas estas explicaciones descansa, del mismo modo que en la argumentación de SCHOPENHAUER, en la evidencia de que el contrato es vinculante porque su vulneración [es] la afirmación de la propia voluntad hasta el extremo de la negación de la ajena y significa su avasallamiento por la artimaña. Aquí no se da ninguna fundamentación, sino solo una traducción de las intuiciones jurídicas básicas común e inalterablemente aceptadas [unverändert übernommenen rechtlichen Grundanschauungen], las cuales posibilitan aquí, precisamente, la fundamentación en la terminología de un sistema filosófico; como ocurre con demasiada frecuencia en los filósofos. Por eso ScHOPENHAUER no llega propiamente a una explicación del Estado, el cual se disuelve para él en una institución de utilidad que "con pleno derecho" puede ejecutar la pena de muerte allí donde nadie debe tener autorización para ello, que asume el papel de juez moral y cuyo derecho no estaría fundado en nada más que en una consideración utilitarista.

La imposibilidad de una fundamentación tal de la autoridad del Estado no pudo pasar desapercibida a un filósofo como Schopenhauer. Pero como consecuencia de ello resulta para él una inconsecuencia palmaria. Literalmente él expone: "Pues por él (el criminal) se ha perturbado la seguridad pública, el fin primordial del Estado, y ésta se ve suprimida si la ley queda sin cumplir; por eso el asesino, su vida, su persona, ha de ser ahora el medio para cumplir la ley y restablecer con ello la seguridad pública; ahora se ha convertido con todo derecho en medio para la ratificación del contrato social que también fue suscrito por él en cuanto ciudadano". El fundamento para la legitimidad [Rechtmäßigkeit] de la pena no descansa, en consecuencia, en la seguridad pública, sino en un contrato; y esto, en comparación con la deducción a partir de las consideraciones de utilidad y seguridad pública, es una construcción cuya heterogeneidad es patente y que el filósofo debió comprender, aunque sin darse cuenta, a pesar de que para él en general todo Derecho y todo Estado solo parecieron ser una cuestión de necesidad práctica. De un modo totalmente consecuente aparece también su ideal del Estado como algo "que se aproxima al país de Jauja". Conforme a esto hay que juzgar el valor de su filosofía del Derecho y del Estado; pues una institución con tal objetivo y con estos efectos debería parecerle a cualquier filósofo y al mismo ScHOPENHAUER algo desdeñable y desprovisto de dignidad moral. Un ideal tal solo pudo ser resultado, sin embargo, de las consideraciones respecto a la necesidad y la seguridad, las cuales presentó para [justificar] la pena y el derecho del Estado a castigar. El reproche y reparo que se oponen a este ideal de Estado, y con ello a

(N. del T.) Cf. A. Schopenhauer: El mundo... Volumen I, op. cit., p. 448 . 
este Estado y a este Derecho mismo, encuentran por eso sus razones, exactamente del mismo modo, en aquellas de las cuales se derivan el Estado y su derecho. Como instituciones de necesidad no tienen ninguna fundamentación, sino que solo [puede] darse una explicación de [su] causa puramente factual.

Respecto a lo expuesto, hay que recordar a todos cómo a Schopenhauer se le imputan todos estos reproches. Pero la fuerza casi violenta de la "formación" con los contenidos jurídico-filosóficos que han sido insertados en su gigantesco sistema por él, es imponente en la misma medida en que, sin embargo, estos significan en este sistema tan solo un ornamento casual y estilístico que pierde su valor y utilidad fuera de este contexto. La pregunta mencionada al comienzo sobre si la filosofía del derecho de Schopenhauer puede ser tomada como fundamentación de un sistema filosófico-jurídico debe ser así contestada negativamente ${ }^{10}$.

10 (N. del A.) También Jung la ha seguido solamente en lo que él presenta como su punto de partida. En el transcurso de su exposición entran siempre nuevos argumentos y finalmente aparece (p. 118) la cultura [Kultur] como fundamento y fin del Derecho, un concepto con el que, tal y como es utilizado por Jung, con toda certeza Schopenhauer no habría estado de acuerdo. 